GONÇALVES, P.A.S.; WERNER, H.; DEBARBA, J.F. Avaliação de biofertilizantes, extratos vegetais e diferentes substâncias alternativas no manejo de tripes em cebola em sistema orgânico Horticultura Brasileira, Brasília, v.22, n.3, p.659-662, jul-set 2004.

\title{
Avaliação de biofertilizantes, extratos vegetais e diferentes substâncias alternativas no manejo de tripes em cebola em sistema orgânico
}

\author{
Paulo A.S. Gonçalves; Hernandes Werner; João F. Debarba \\ EPAGRI, C. Postal 121, 88400-000 Ituporanga-SC; E-mail: pasg@epagri.rct-sc.br
}

\begin{abstract}
RESUMO
Avaliou-se substâncias alternativas no manejo de tripes (Thrips tabaci Lind.), em cebola, cv, Crioula, no sistema orgânico. Os experimentos foram conduzidos na EPAGRI, Ituporanga (SC). Os períodos entre transplante e colheita foram de 11/09/1996 a 10/01/1997 e 13/08/1997 a 11/12/1997. O delineamento foi de blocos ao acaso com 8 tratamentos em 1996 e 12 tratamentos em 1997 e quatro repetições. Em 1996 os tratamentos incluíram o biofertilizante anaeróbico $50 \%$, biofertilizante aeróbico $5 \%$, sulfato de manganês $1 \%$, extrato hidroalcoólico de própolis $0,2 \%$, macerado de ervas ("fersoral") $2 \%$ e $4 \%$, extrato de fumo (Nicotiana tabacum) $2 \mathrm{~L} \mathrm{ha}^{-1}+1 \%$ detergente neutro, testemunha sem aplicação. Em 1997 os tratamentos incluíram o macerado de ervas ("fersoral") 5\% 10\%, enxofre pó molhável $0,25 \%$ + extrato hidroalcoólico de própolis $0,2 \%$ + extrato de samambaia $3 \%$, biofertilizante anaeróbico $50 \%$, biofertilizante aeróbico $5 \%$, extrato de losna (Artemisia verlotorum) 3\%, extrato de timbó (Ateleia glazioviana) $0,5 \%$, extrato de samambaia (Pteridium aquilinum) $10 \%$, extrato de erva-de-santa-maria (Chenopodium ambrosioides) 10\%, extrato de cinamomo (Melia azedarach) 10\%, extrato de camomila (Matricaria chamomilla) 5\%, testemunha sem aplicação. Para aplicação dos produtos empregou-se pulverizador de pressão constante a base de $\mathrm{CO}_{2}$. Os tratamentos não causaram redução significativa na incidência de tripes e aumentos significativos na produtividade.
\end{abstract}

Palavras-chave: Allium cepa, Thrips tabaci, agricultura orgânica, inseto, agroecologia.

\begin{abstract}
Evaluation of biofertilizers, plant extracts, and some alternative substances to manage onion thrips in organic agriculture system
\end{abstract}

Alternative substances to manage thrips population (Thrips tabaci Lind.) on onion, in an organic agriculture system were evaluated. The experiments were carried out in Ituporanga, Santa Catarina State, Brazil. Plants of onion cv. Crioula were transplanted into two fields on $9^{\text {th }}$ September/96 and $13^{\text {th }}$ August/97 and harvested respectively on $10^{\text {th }}$ January/97 and $11^{\text {th }}$ December/97. A randomized blocks with four replicates were used in both experiments. In 1996 the treatments included the anaerobic liquid biofertilizer at $50 \%$, aerobic liquid biofertilizer at $5 \%$, manganese sulfate at $1 \%$, hydroalcoholic extract of propolis at $0,2 \%$, macerate of herbs at $2 \%$ and $4 \%$, tobacco extract (Nicotiana tabacum) $2 \mathrm{~L} \mathrm{ha}^{-1}+$ neutral detergent at $1 \%$, and no spray. In 1997, the treatments were: macerate of herbs $5 \%$ and $10 \%$; sulfur waterable powder $0,25 \%+$ propolis hydroalcoholic extract $0,2 \%+$ extract of fern (Pteridium aquilinum) 3\%; anaerobic liquid biofertilizer $50 \%$; extract of wormseed goosefoot (Chenopodium ambrosioides) $10 \%$; aerobic liquid biofertilizer 5\%; extract of Ateleia glazioviana $0,5 \%$; extract of fern (Pteridium aquilinum) $10 \%$; extract of chinaberry (Melia zedarach) 10\%; extract of camomile (Matricaria chamomilla) $5 \%$; and control without spray. The products were applied using a $\mathrm{CO}_{2}$ sprayer with constant pressure. The different treatments did not cause significant reduction in the thrips population nor any increase in yield in comparison to control treatment, without spray.

Keywords: Allium cepa, Thrips tabaci, organic agriculture, insect, agroecology.

\section{(Recebido para publicação em 29 de abril de 2003 e aceito em 30 de março de 2004)}

A cultura da cebola é umas das prin cipais hortaliças plantadas em Santa Catarina sendo o Estado um dos principais produtores em volume e área plantada (Boeing, 2003). O tripes (Thrips tabaci Lind.), ou piolho como é popularmente conhecido na região é a principal praga da cultura (EPAGRI, 2000). Na fase pós-transplante é necessário desenvolver estratégias alternativas ao manejo de tripes, pois frequientemente atinge níveis de dano econômico (Gonçalves, 1997b). Recentemente, tem-se observado que as plantas toleram o dano do inseto em solos manejados sob plantio direto e altos níveis de matéria orgânica (Gonçalves, 1998).

O uso de biofertilizantes tem sido recomendado em agricultura orgânica como forma de manter o equilíbrio nutricional de plantas e torná-las menos predispostas à ocorrência de pragas e patógenos (Pinheiro e Barreto, 1996; Penteado, 1999; Bettiol, 2001; Santos, 2001). As principais causas da inibição do desenvolvimento de patógenos pelos biofertilizantes seria o efeito fungistático e bacteriostático, principalmente pela presença da bactéria, Bacillus subtilis (originária do rúmen de bovinos), que sintetiza substâncias antibióticas, aliado a diversos nutrientes, vitaminas e aminoácidos (Pinheiro e Barreto, 1996; Bettiol, 2001; Santos, 2001). A ação dos biofertilizantes sobre os insetos é de natureza repelente, devido a substâncias voláteis, como álcoois, fenóis e ésteres, equilíbrio nutricional das plantas e/ou efeito mecânico por adesividade e desidratação (Santos, 2001).

O uso de extratos de plantas tem sido fomentado recentemente para o manejo de pragas em sistemas ecológicos, com o intuito de reduzir a dependência do agricultor de insumos externos à propriedade (Hernandez, 1996; Abreu Jr., 1998; Burg e Mayer, 1999; Penteado, 1999).

O objetivo deste trabalho foi avaliar o uso de substâncias alternativas para o controle de tripes em cebola sob manejo orgânico, visando reduzir a dependência econômica do agricultor.

\section{MATERIAL E MÉTODOS}

O trabalho foi realizado durante dois anos na EPAGRI em Ituporanga, SC. Os 
períodos entre transplante e colheita foram de 11/09/1996 a 10/01/1997 e 13/ 08/1997 a 11/12/1997. A cultivar Crioula foi plantada em delineamento experimental o de blocos ao acaso com quatro repetições, parcelas de 2,8 x 3,0 m, espaçamento de $40 \times 7,5 \mathrm{~cm}$ e área útil de 2,0 $\mathrm{m} \mathrm{x} \mathrm{3,0} \mathrm{m}$ ondee a bordadura foi uma linha em cada extremidade da parcela. A análise de solo revelou: $\mathrm{pH}$ (água), 6; pH (SMP), 6; P, + 50 mg dm ${ }^{-3}$; $\mathrm{K},+150 \mathrm{mg} \mathrm{dm}^{-3}$; matéria orgânica, 55

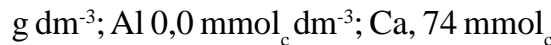
$\mathrm{dm}^{-3} ; \mathrm{Mg}, 57 \mathrm{mmol}_{\mathrm{c}} \mathrm{dm}^{-3}$; argila, $250 \mathrm{~g}$ $\mathrm{dm}^{-3}$. Os dados climatológicos durante o período de realização dos experimentos foram respectivamente para os anos de 1996 e 1997, temperaturas média $\left(18,9^{\circ} \mathrm{C} ; 18,3^{\circ} \mathrm{C}\right)$, máxima $\left(25,1^{\circ} \mathrm{C}\right.$; $\left.24,3^{\circ} \mathrm{C}\right)$, mínima $\left(14,9^{\circ} \mathrm{C} ; 14,8^{\circ} \mathrm{C}\right)$, precipitação média acumulada $(165,6 \mathrm{~mm}$; $186,3 \mathrm{~mm})$, umidade relativa $(80,8 \%$; $83,0 \%)$. A área experimental em questão era conduzida historicamente de maneira convencional, ou seja com aplicação de adubos minerais, irrigação e agrotóxicos. Portanto, estes experimentos foram realizados sob condições da transição do manejo convencional para orgânico (sem aplicação de agroquímicos) na cultura. Em 1996 o manejo do solo foi plantio sobre palhada de ervilhaca (Vicia sp.) e em 1997 foi realizado através do plantio direto, sobre palhada de mucuna (Stizolobium sp.), e milho, e a adubação realizada superficialmente a lanço, com esterco de suíno fresco na dosagem de $7,7 \mathrm{~kg}$ $\mathrm{m}^{-2}$ (contendo: $\mathrm{N}=31,33 \mathrm{~g} \mathrm{~kg}^{-1}, \mathrm{P}=$ $21,34 \mathrm{~g} \mathrm{~kg}^{-1}, \mathrm{~K}=2,2 \mathrm{~g} \mathrm{~kg}^{-1}, \mathrm{Ca}=45,4 \mathrm{~g}$ $\mathrm{kg}^{-1}, \mathrm{Mg}=4,0 \mathrm{~g} \mathrm{~kg}^{-1}, \mathrm{Fe}=3112 \mathrm{mg} \mathrm{kg}^{-1}$, $\mathrm{Mn}=330 \mathrm{mg} \mathrm{kg}^{-1}, \mathrm{Zn}=394 \mathrm{mg} \mathrm{kg}^{-1}$, $\mathrm{Cu}=504 \mathrm{mg} \mathrm{kg}^{-1}, \mathrm{~B}=16 \mathrm{mg} \mathrm{kg}^{-1}$ ).

Os tratamentos utilizados em 1996 foram o biofertilizante anaeróbico $50 \%$, bioferilizante aeróbico $5 \%$, sulfato de manganês $1 \%$, extrato hidroalcoólico de própolis $0,2 \%$, fersoral $2 \%$ e fersoral $4 \%$, extrato de fumo (Nicotiana tabacum) $2 \mathrm{~L} \mathrm{ha}^{-1}+1 \%$ detergente neutro e testemunha sem aplicação. $\mathrm{O}$ biofertilizante anaeróbico foi composto por $20 \mathrm{~kg}$ de esterco bovino em $40 \mathrm{~L}$ de água que permaneceram em processo de fermentação por 5 dias, após adicionouse $1 \mathrm{~kg}$ de superfosfatotriplo, $400 \mathrm{~g}$ de sulfato de manganês, $40 \mathrm{~g}$ de Solubor $\circledR$
(20,0\% de B), $2 \mathrm{~kg}$ de calcário dolomítico, $1 \mathrm{~kg}$ de cal virgem (adicionado 1 semana após aos demais componentes com a finalidade de elevar o ph da solução para 7,0) em 190 L de água em um tambor de $200 \mathrm{~L}$ vedado com tampa. O biofertilizante aeróbico foi composto por $40 \mathrm{~kg}$ de esterco em 90 L de água, e para ativar a fermentação foram usados $1,5 \mathrm{~kg}$ de açúcar e $3 \mathrm{~L}$ de leite, após uma semana foram adicionados semanalmente as fontes de nutrientes (uma por vez) na seguinte ordem: $600 \mathrm{~g}$ de boro, $1 \mathrm{~kg}$ de cloreto de cálcio, $1 \mathrm{~kg}$ de sulfato de magnésio, 100 $\mathrm{g}$ de molibdato de sódio, $1 \mathrm{~kg}$ de sulfato de manganês, $0,5 \mathrm{~kg}$ de sulfato de zinco, $200 \mathrm{ml}$ de Solubor ${ }^{\circledR}$. Os nutrientes foram misturados na primeira semana com $15 \mathrm{~L}$ de água, $0,5 \mathrm{~kg}$ de açúcar, $1 \mathrm{~L}$ de leite bovino, $100 \mathrm{~L}$ de sangue bovino e 20 L de esterco fresco. Após 75 dias para reativar a fermentação adicionouse respectivamente $20 \mathrm{~L}$ de esterco fresco, 1,5 kg de açúcar, $3 \mathrm{~L}$ de leite, $1 \mathrm{~L}$ de sangue fresco de bovino, completado com água. Após 163 dias adicionou-se $20 \mathrm{~g}$ de sulfato de cobalto, $100 \mathrm{~g}$ de sulfato de ferro associados a $30 \mathrm{~L}$ de água, $15 \mathrm{~kg}$ de esterco fresco e $0,5 \mathrm{~kg}$ de açúcar. O extrato hidroalcoólico de própolis foi obtido da mistura dos extratos alcoólico (maceração de $200 \mathrm{~g}$ própolis moído em 1 litro de álcool de cereais $70^{\circ} \mathrm{GL}$ durante 20 dias) e aquoso (mesmo procedimento anterior, porém com maceração em água destilada) na proporção 1:2. O fersoral, macerado de ervas idealizado por técnicos da região Alto Vale do Itajaí, SC, foi composto de $1,5 \mathrm{~kg}$ de folhas de urtiga (Urtica $\mathrm{sp}$.); $250 \mathrm{~g}$ de flores de camomila (Matricaria chamomilla); $1 \mathrm{~kg}$ de fumo de corda; $250 \mathrm{~g}$ de bulbos de alho (Allium sativum); $2 \mathrm{~L}$ de sangue bovino fresco e $100 \mathrm{~L}$ de soro de leite, fermentados anaerobicamente por 90 dias antes do uso. O extrato de fumo foi obtido através da edição de $300 \mathrm{~g}$ de fumo de rolo de água, sendo fervido a mistura por 10 minutos. Posteriormente o extrato foi filtrado em papel de filtro e adicionados $100 \mathrm{ml}$ de álcool $96^{\circ} \mathrm{GL}$ por litro de extrato.

Os tratamentos em 1997 foram o fersoral 5\%, fersoral 10\%, enxofre pó molhável $0,25 \%+$ extrato hidroalcoólico de própolis $0,2 \%$ + extrato de samambaia $3 \%$, biofertilizante anaeróbico $50 \%$, biofertilizante aeróbico 5\%, extrato de losna (Artemisia verlotorum) $3 \%$, extrato de timbó (Ateleia glazioviana) 0,5\%, extrato de samambaia (Pteridium aquilinum) 10\%, extrato de erva-de-santa-maria (Chenopodium ambrosioides) 10\%, extrato de cinamomo (Melia azedarach) $10 \%$, extrato de camomila (Matricaria chamomilla) $5 \%$ e testemunha sem aplicação. Os biofertilizantes usados em 1997 foram remanescentes de 1996. Neste ano o fersoral foi composto por: $300 \mathrm{~g}$ de folha seca de urtiga, (Urtica sp.), $1 \mathrm{~kg}$ de flores secas de camomila (M. chamomilla), $500 \mathrm{~g}$ de bulbos de alho (A. sativum) cortados em pequenos pedaços, $10 \mathrm{~kg}$ de folhas verdes de samambaia ( $P$. aquilinum), $6 \mathrm{~kg}$ de folhas verdes de losna (A. verlotorum), 2 $\mathrm{kg}$ de folhas secas de erva-de-santamaria (C. ambrosioides), $3 \mathrm{~L}$ de sangue bovino, $200 \mathrm{~L}$ de soro de leite, fermentados anaerobicamente 90 dias antes do uso. O extrato de samambaia foi obtido pela maceração por 8 dias de $100 \mathrm{~g}$ de folhas secas em $700 \mathrm{ml}$ de água destilada e $300 \mathrm{ml}$ de álcool comum $98^{\circ} \mathrm{GL}$.

As pulverizações foram realizadas em 1996 nas datas de 14/10, 27/10, 12/ 11, 25/11, 03/12; e em 1997 nas datas de 13/10 (pré-contagem), 16/10, 27/10, $10 / 11,13 / 11,04 / 12$. O equipamento usado nas aplicações dos tratamentos foi um pulverizador de pressão constante por $\mathrm{CO}_{2}$ e munido com bico leque XR 110.015 VS .

As variáveis observadas foram a contagem de ninfas de T. tabaci a campo em 5 plantas parcela ${ }^{-1}$ com o auxílio de lupa manual ( $3 \mathrm{x}$ de aumento), a produtividade $\left(\mathrm{t} \mathrm{ha}^{-1}\right)$ foi avaliada em 60 bulbos parcela ${ }^{-1}$, selecionando-se entre estes apenas os comerciais (maiores que $3,5 \mathrm{~cm}$ de diâmetro). O período de avaliação da incidência do inseto foi próximo a segunda quinzena de outubro, fase de infestações severas no Alto Vale do Itajaí segundo Gonçalves (1997a). As plantas estavam com 33 e 61 dias após o transplante respectivamente em 1996 e 1997.

Para a análise dos dados o número médio de ninfas de T. tabaci planta $^{-1}$ foi transformado para $\log (\mathrm{x}+0,5)$ e a pro- 
Tabela 1. Número médio de ninfas de tripes, e porcentagem de eficiência Abbott (EFAB\%) e Henderson e Tilton (EFHT\%); produtividade média de cebola e massa fresca de bulbos. Ituporanga, EPAGRI, 1996.

\begin{tabular}{|c|c|c|c|c|c|}
\hline Tratamentos & Ninfas & (EFAB\%) & (EFHT\%) & $\begin{array}{c}\text { Produtividade } \\
\text { (t.ha-1) }\end{array}$ & $\begin{array}{l}\text { Massa fresca } \\
\text { de bulbos (g) }\end{array}$ \\
\hline Biofertilizante anaeróbico $50 \%$ & $24,9 \mathrm{~ns}^{*}$ & 0 & 17,7 & $8,2 \mathrm{~ns}^{*}$ & $49,3 \mathrm{~ns}^{*}$ \\
\hline Biofertilizante aeróbico $5 \%$ & 19,0 & 7,8 & 14,0 & 7,3 & 44,5 \\
\hline Sulfato de Manganês $1 \%$ & 19,1 & 7,3 & 14,3 & 8,8 & 54,6 \\
\hline Extrato de própolis $0,2 \%$ & 22,2 & 0 & 8,5 & 6,8 & 42,5 \\
\hline Fersoral $2 \%$ & 22,4 & 0 & 16,5 & 11,3 & 54,7 \\
\hline Fersoral $4 \%$ & 22,1 & 0 & 12,8 & 12,9 & 57,3 \\
\hline Extrato de fumo 2 I.ha-1 + detergente neutro $1 \%$ & 23,6 & 0 & 11,4 & 7,1 & 52,2 \\
\hline Testemunha & 20,6 & & & 7,7 & 51,5 \\
\hline$\overline{C . V \%}$ & 22,4 & & & 48,8 & 23,3 \\
\hline
\end{tabular}

*ns, a diferença entre tratamentos foi não significativa pelo teste de $\mathrm{F}$ ao nível de $5 \%$ de probabilidade.

Tabela 2. Número médio de ninfas de tripes, Thrips tabaci Lind, e porcentagem de eficiência Abbott (EFAB\%) e Henderson \& Tilton (EFHT\%) de substâncias alternativas; produtividade média de cebola (t.ha-1 ${ }^{-1}$ e peso médio de bulbos. Ituporanga, EPAGRI, 1997.

\begin{tabular}{|c|c|c|c|c|c|}
\hline Tratamentos & Ninfas & (EFAB\%) & (EFHT\%) & $\begin{array}{l}\text { Produtividade } \\
\left(\text { t. ha }^{-1}\right)\end{array}$ & $\begin{array}{l}\text { Peso de } \\
\text { bulbos (g) }\end{array}$ \\
\hline Fersoral $5 \%$ & $28,6 \mathrm{NS}^{*}$ & 0 & 9,4 & $19,6 \mathrm{NS}^{*}$ & $67,5 \mathrm{NS}^{*}$ \\
\hline Fersoral $10 \%$ & 26,3 & 0 & 14,3 & 19,7 & 66,9 \\
\hline $\begin{array}{l}\text { Enxofre PM 0,25\% + Extrato de própolis } 0,2 \% \text { + Extrato } \\
\text { de samambaia } 3 \%\end{array}$ & 26,2 & 0 & 3,4 & 19,8 & 64,9 \\
\hline Biofertilizante anaeróbico $50 \%$ & 24,1 & 3,6 & 10,0 & 20,4 & 67,0 \\
\hline Biofertilizante aeróbico $5 \%$ & 24,2 & 3,2 & 6,8 & 17,8 & 61,6 \\
\hline Extrato de losna $3 \%$ & 25,9 & 0 & 10,6 & 22,4 & 70,7 \\
\hline Extrato de timbó $0,5 \%$ & 28,2 & 0 & 1,3 & 18,7 & 63,4 \\
\hline Extrato de samambaia $10 \%$ & 26,2 & 0 & 9,7 & 19,2 & 64,7 \\
\hline Extrato de erva-de-santa-maria $10 \%$ & 30,4 & 0 & 8,4 & 17,9 & 63,7 \\
\hline Extrato de cinamomo $10 \%$ & 24,5 & 2 & 11,1 & 20,3 & 66,3 \\
\hline Extrato de camomila 5\% & 29,6 & 0 & 5,7 & 19,0 & 67,5 \\
\hline Testemunha & 25,0 & 0 & & 20,7 & 66,8 \\
\hline C.V\% & 12,9 & & & 9,4 & 6,6 \\
\hline
\end{tabular}

*ns, a diferença entre tratamentos foi não significativa pelo teste de $\mathrm{F}$ ao nível de $5 \%$ de probabilidade.

dutividade $\left(\mathrm{t} \mathrm{ha}^{-1}\right)$, peso médio de bulbo (g) foram submetidos a análise de variância e as médias comparadas pelo teste de Tukey a $5 \%$. A eficiência dos tratamentos no controle de tripes foi determinada pelas fórmulas de Abbott, $\% \mathrm{E}=(\mathrm{T}-\mathrm{I}) / \mathrm{T} X 100$, e de Henderson e Tilton, $\% \mathrm{E}=[1-(\mathrm{Id} \times \mathrm{Ta} / \mathrm{Ia} \times \mathrm{Td})] \mathrm{x}$ 100, citadas por Nakano et al. (1981), onde $\% \mathrm{E}=$ porcentagem de eficiência, $\mathrm{T}=$ número de insetos na testemunha sem aplicação, I= número de insetos no tratamento com pulverização, $\mathrm{Id}=$ número de insetos no tratamento com pulverização após aplicação, Ia= número de insetos no tratamento com pulverização antes da aplicação, Td= número de insetos na testemunha sem aplicação após pulverizar os demais tratamentos, $\mathrm{Ta}=$ número de insetos na testemunha sem aplicação antes da pulverização nos demais tratamentos.

\section{RESULTADOS E DISCUSSÃO}

Os tratamentos não apresentaram efeito significativo no controle populacional de tripes (Tabelas 1 e 2). A eficiência através da fórmula de Abbott foi d" $7,8 \%$, a maioria dos tratamentos não apresentou eficiência $(\% \mathrm{E})$, exceto o biofertilizante aeróbico $5 \%$ $(\% \mathrm{E}=7,8 \%)$ e sulfato de manganês $1 \%$ $(\% \mathrm{E}=7,3 \%)$ em 1996, e em 1997 biofertilizantes anaeróbico $50 \%(\% \mathrm{E}=$ $3,6 \%)$ e aeróbico $5 \%(\% \mathrm{E}=3,2 \%)$, e extrato de cinamomo $10 \%(\% \mathrm{E}=2 \%)$ (Tabelas 1 e 2). A eficiência através da fórmula de Henderson e Tilton foi mais alta em 1996 para biofertilizante anaeróbico $50 \%(\% \mathrm{E}=17,7 \%)$ e em 1997 para fersoral $10 \%(\% \mathrm{E}=14,3 \%)$ (Tabelas 1 e 2). Os níveis de eficiência obtidos pela fórmula de Abbott (3,2 a $7,8 \%$ ) foram inferiores aos observados quando utilizou-se Henderson e Tilton (1,3 a 17,7\%) (Tabelas 1 e 2). Provavelmente isto ocorreu porque tais substâncias não possuem alto impacto inseticida, o que seria detectado pela fórmula de Abbott, pois o tratamento com aplicação é comparado diretamente com a testemunha, porém devem promover alterações na fisiologia da planta que inibam o estabelecimento do inseto no decorrer do ciclo, como observado quando usou-se a fórmula de Henderson e Tilton, que considera a evolução do desenvolvimento do inseto tanto no tratamento com aplicação como também na 
testemunha. No manejo de tripes em produção orgânica de cebola tem sido sugerido o uso de biofertilizante $3 \%$ associado a calda sulfocálcica $5 \%$ e farinha de trigo $2 \%$ ou 3 a $5 \%$ de alhol (espalhante adesivo idealizado pelo autor) para severas infestações para as condições da região Centro-Serra, RS (Claro, 2001). Provavelmente seja necessário ajustes no biofertilizante usado no presente trabalho para maiores níveis de eficiência, como alterações de formulação e dosagens ou mesmo utilizá-lo associado a outras substâncias. Santos (1995) observou que os biofertilizantes têm efeito inseticida sobre insetos de tegumento mole na fase larval, enquanto para adultos com tegumento duro o efeito seria repelente. Ainda de acordo com Santos (1995) os biofertilizantes em altas concentrações (e"50\%) promovem o controle mecânico de insetos por contato e asfixia, a medida que se dilui o efeito passa a ser repelente. Em contraste, Picanço et al. (1997) não observaram efeito significativo da aplicação de biofertilizante supermagro isoladamente ou associado a calda viçosa, calda viçosa + extrato de eucalipto e calda viçosa + Bacillus thuringiensis, sobre a incidência da traça-do-tomateiro, Tuta absoluta. O objetivo da utilização de biofertilizantes em sistemas agroecológicos de produção é a atuação como defensivo e não obter altos níveis de controle como é a aplicação de agrotóxicos em sistemas convencionais (CAE Ipê, 1997). O princípio da utilização de biofertilizantes seria a obtenção do equilíbrio nutricional das plantas e consequentemente resistência às doenças e pragas como ressaltado por Chaboussou (1987) na teoria da trofobiose. Primavesi (1988) enfatizou a importância do valor biológico dos alimentos, definido como a capacidade da planta de sintetizar todas as substâncias de acordo com o seu potencial genético, desde que se desenvolva sob condições de equilíbrio nutricional.

A produtividade e massa fresca de bulbos não foram incrementados significativamente em relação a testemunha (Tabelas 1 e 2). Convém ressaltar, que devido a área experimental estar em processo de transição do manejo convencional para orgânico, pode ter favorecido a produtividade similar entre tratamentos, pois as condições ecológicas do solo e demais funções ecológicas (incidência de inimigos naturais, por exemplo) ainda estavam em processo de recuperação. Picanço et al. (1997) também não observaram aumento significativo de produtividade em tomateiro com o biofertilizante supermagro usado isoladamente, porém em associação com calda viçosa e Bacillus thuringiensis houve superioridade significativa com relação a testemunha. Werner (1996) também não verificou incremento de produtividade com sulfato de manganês em pulverização foliar de $0,5 \%$ a 2,5\%, embora observasse melhor desenvolvimento de plantas e de bulbos de cebola nas áreas tratadas, e sugeriu estudos com teores mais elevados do nutriente, bem como interação com adubação de base. Portanto, o uso de tais substâncias em produção orgânica de cebola não se justificaria com o intuito de aumentar-se produtividade, uma vez que não alteraram o rendimento da cultura, além de aumentarem o uso de mão de obra, um dos pontos críticos de adoção deste sistema pelos agricultores, segundo Parizotto e Lovato (2002). Porém, deve ser considerado que como o objetivo da maioria das substâncias alternativas utilizadas em sistemas agroecológicos é promover o equilíbrio nutricional das plantas, seria interessante realizar em futuros trabalhos análises da qualidade nutricional do alimento produzido, bem como conservação pós-colheita, pois embora possa não haver incremento significativo de produtividade, a qualidade fisiológica do alimento produzido pode estar sendo alterada. Os tratamentos utilizados no presente trabalho não apresentaram eficiência no controle de tripes e nem incrementaram a produtividade da cultura, portanto não é recomendável a sua utilização em sistemas orgânicos tendose por objetivo estas variáveis.

\section{AGRADECIMENTOS}

Ao técnico agrícola Marcelo Pitz e sua equipe pelo apoio na condução do trabalho. Ao pesquisador Engenheiro Agrônomo Pedro Boff pela sugestões na redação do texto.

\section{LITERATURA CITADA}

ABREU Jr., H. (Coord.) Práticas alternativas de controle de pragas e doenças na agricultura: coletânea de receitas. Campinas: EMOPI, 1998. 112 p. BETTIOL, W. Resultados de pesquisa com métodos alternativos para o controle de doenças de plantas. In: HEIN, M. (org.) Resumos do $1^{\circ} \mathrm{En}$ contro de Processos de Proteção de Plantas: controle ecológico de pragas e doenças. Botucatu, Agroecológica, 2001. p.125-135.
BOEING, G. Cebola - IBGE reavalia resultados da safra 01/02. Informe conjuntural, v.21, n.913, p.6, 2003.

BURG, I.C.; MAYER, P.H. (Org.) Manual de alternativas ecológicas para prevenção e controle de pragas e doenças: (caldas, biofertilizantes, fitoterapia animal, formicidas e defensivos naturais). 7. ed. Francisco Beltrão: ASSESOAR/ COOPERIGUAÇU, 1999. 153 p

CAE Ipê. Biofertilizantes enriquecidos: caminho sadio da nutrição e proteção das plantas. Ipê: CAE Ipê, 1997. 24 p.

CHABOUSSOU, F. Plantas doentes pelo uso de agrotóxicos: a teoria da trofobiose. 2 ed. Porto Alegre: L \& PM, 1987. 256 p.

CLARO, S.A. Referenciais tecnológicos para a agricultura familiar ecológica: a experiência da região Centro-Serra do Rio Grande do Sul. Porto Alegre: EMATER/RS-ASCAR, 2001. 250 p.

EPAGRI. Sistema de produção para cebola: Santa Catarina. (3. revisão). Florianópolis: EPAGRI, 2000. 91 p.

GONÇALVES, P.A.S. Flutuação populacional de tripes, Thrips tabaci Lind., em cebola em Ituporanga, Santa Catarina. Anais da Sociedade Entomológica do Brasil, v.26, n.2, p.365-369, 1997a.

GONÇALVES, P.A.S. Determinação de nível de dano econômico de Thrips tabaci Lind., na cultura da cebola. In: CONGRESSO BRASILEIRO DE ENTOMOLOGIA, 16., Salvador. Resumos... Salvador: SEB/EMBRAPA - CNPMF, 1997b. 400 p. p.287.

GONÇALVES, P.A.S. Determinação de nível de dano econômico de tripes em cebola. Horticultura Brasileira, Brasília, v.16, n.2, p.128-131, 1998.

HERNANDEZ, C.R. (Comp.) Memoria del curso de: control alternativo de insetos plaga. Tepotzotlan: Colegio de Postgraduados y Fundacion Mexicana para la Educacion Ambiental A.C., 1996.114 p.

NAKANO, O.; SILVEIRA NETO, S.; ZUCCHI, R.A. Entomologia Econômica. Piracicaba: Livroceres, 1981. 314 p.

PARIZOTTO, C.; LOVATO P.E. Levantamento preliminar sobre o sistema de produção de cebola do Alto Vale do Itajaí. Agropecuária Catarinense, Florianópolis, v.15, n.1, p.50-52, 2002.

PENTEADO, S.R. Defensivos alternativos e naturais: para uma agricultura saudável. Campinas, Sílvio Roberto Penteado, 1999. 79 p.

PICANÇO, M.C.; FALEIRO, F.G.; PALLINI FILHO, A.; MATIOLI, A.L. Perdas na produtividade do tomateiro em sistemas alternativos de controle fitossanitário. Horticultura Brasileira, Brasília, v.15, n.2, p.88-91, 1997.

PINHEIRO S.; BARRETO, S.B. MB-4: Agricultura sustentável, trofobiose e biofertilizantes. Florianópolis: Fundação Juquira candiru, Mibasa, 1996. 273 p.

PRIMAVESI, A.M. Manejo ecológico de pragas e doenças. São Paulo: Nobel, 1988. 137 p. SANTOS, A.C.V. Biofertilizante líquido: o defensivo agrícola da natureza. $2^{\mathrm{a}}$ ed. rev. Niterói: EMATER-Rio, 1995. 16 p.

SANTOS, A.C.V. A ação múltipla do biofertilizante líquido como ferti e fitoprotetor em lavouras comerciais. In: HEIN, M. (org.) Resumos do $1^{\circ}$ Encontro de Processos de Proteção de Plantas: controle ecológico de pragas e doenças. Botucatu, Agroecológica, 2001. p.91-96.

WERNER, H. Efeito de níveis de manganês na adubação foliar de cebola. In: REPECEM: Reunião de Pesquisa de cebola no MERCOSUL, 1., 1996, Ituporanga. Resumos... Ituporanga: EPAGRI, 1996. p.53. 